\title{
Proposta Metodológica para Identificação de vilas e povoados mineiros localizados mais próximos das sedes municipais de outros municípios vizinhos
}

\section{Methodological proposal for identification of villages and hamlets nearer to other borderer municipalities' headquarters in Minas Gerais}

Gabriel Luís Nogueira de Oliveira

Graduando em Geografia pela UFMG

gab.nogueira1@hotmail.com

\section{Aliane Maria Motta Baeta \\ Mestre em Geografia pela PUC Minas, Diretora de Ciências \\ Geodésicas e Ordenamento Territorial - IGTEC \\ aliane.baeta@iga.br}

Brenner Henrique Maia Rodrigues

Mestre em Análise Ambiental pela UFMG

Diretor da empresa Gestão de Projetos Ambientais Ltda.

brenner@gpa.eng.br

Marcos Antônio Nunes

Mestre e Doutorando em Geografia pela UFMG

Coordenador do Setor de Geografia - IGTEC

marcos.geoman@gmail.com

Ralfo Edmundo da Silva Matos

Doutor em Demografia e Mestre em Economia Urbana e Regional - Cedeplar/UFMG

Professor Titular do Departamento de Geografia da UFMG/IGC

ralfo@geo.igc.ufmg.br

Recebido para revisão em 06/05/2015 e aceito para publicação em 10/06/2015

\begin{abstract}
Resumo
Esta pesquisa é o resultado de estudos realizados para o projeto "Implantação do Laboratório de Atendimento às Demandas de Limites Municipais e Distritais de Minas Gerais", executado pelo Instituto de Geoinformação e Tecnologia (IGTEC), da Secretaria de Estado de Ciência, Tecnologia e Ensino Superior do Governo de Minas Gerais. O projeto demandou o desenvolvimento de uma metodologia através da qual pudesse identificar os casos de ocorrência das vilas (sedes distritais) e dos povoados dos municípios mineiros que se encontram a distâncias inferiores às das sedes de municípios vizinhos em relação às suas respectivas sedes municipais. A metodologia se pautou pelas distâncias em linha reta, obtidas a partir dos centroides dos setores censitários dos municípios mineiros. O levantamento desses casos é importante para a compreensão do transbordamento de serviços intermunicipais e subsidiar a organização territorial do estado de Minas Gerais.
\end{abstract}

Palavras-chave: Sedes Municipais; Vilas e Povoados; Setores censitários; Minas Gerais.

\begin{abstract}
This research is the result of studies for the project "Implantação do Laboratório de Atendimento às Demandas de Limites Municipais e Distritais de Minas Gerais", executed by Instituto de Geoinformação e Tecnologia (IGTEC), part of the State Secretariat of Science, Tecnology and Superior Education of Minas Gerais government. The project required the development of a
\end{abstract}


methodology to identify cases of occurrence of villages (districtal headquarters) and hamlets of Minas Gerais' municipalities which are located closer to the other municipality headquarter instead of the own headquarter. The methodology was based by the distances in a straight line, obtained from the census sectors' centroids. The survey of these cases is important to understand the overflow of intercity services and to support the territorial organization of the state of Minas Gerais.

Keywords: Municipal headquarters; Villages and hamlets; Census sectors; Minas Gerais.

\section{INTRODUÇÃO}

O Instituto de Geoinformação e Tecnologia (IGTEC) ${ }^{1}$, outrora Instituto de Geociências Aplicadas (IGA), é o órgão responsável, entre outros, pelo estudo técnico e descritivo para a alteração de limites intra e intermunicipais, e para a demarcação de limites para fins de criação de novos distritos em Minas Gerais ${ }^{2}$. No entanto, para este expediente, cabe ao legislativo municipal os entendimentos e as discussões acerca dos objetivos políticos, conforme o art. 30 da Constituição Federal e em observância às respectivas legislações estaduais.

Neste caso, o IGTEC subsidia tecnicamente a discussão para o fracionamento municipal, uma vez que o texto da lei de alteração municipal deverá garantir que tal limite seja lançado de forma inteligível na base da divisão territorial de Minas Gerais (IGA, 2012).

Minas Gerais é a unidade federativa brasileira que detém o maior número de municípios e, por conseguinte, de distritos. Em 2014 o estado passou a contar com 1.680 distritos, distribuídos pelos 853 municípios (IGTEC, 2015). O fracionamento municipal em distritos é condição sine qua non para a criação de outros municípios. Daí constituir uma das razões do crescimento indiscriminado do número de distritos após a Constituição de 1988, não apenas em Minas Gerais, mas também em outros estados brasileiros (NUNES; GARCIA, 2014).

Esses sucessivos fracionamentos são em geral de caráter político, e por isso nem sempre são acompanhados de uma lógica que privilegia o ordenamento territorial, nem tampouco a distribuição da infraestrutura no território municipal. Isso compromete o acesso aos equipamentos urbanos e aos serviços municipais, além de alterar substancialmente a estética dos polígonos distritais, o que resulta em formas bizarras, como será exemplificado em uma seção subsequente.

Embora as alterações de limites municipais estejam sendo dificultadas pela Constituição Federal, por falta de regulamentação do art. 18 e consenso entre o Legislativo e o Executivo

\footnotetext{
${ }^{1}$ O IGTEC surgiu a partir da incorporação da Fundação Centro Tecnológico de Minas Gerais (CETEC) pelo Instituto de Geociências Aplicadas, em 2014, tendo em vista a orientação do governo estadual em reduzir despesas com a máquina pública.

${ }^{2}$ Em conformidade com o Decreto Estadual no 44.852 de 2 de julho de 2008, art. 2, inciso XII.
} 
federais $^{3}$, existem estudos de alteração que foram solicitados e realizados pelo então IGA, tendo sido votados pelas câmaras municipais dos municípios requerentes.

Em todos esses casos, o processo de alteração municipal ficou retido na Assembleia Legislativa de Minas Gerais, que não homologa tais alterações, pela falta de regulamentação da Constituição Federal, após a Emenda Constitucional no 15.

\subsection{O surto e o freio à corrida emancipacionista}

Entre o período censitário de 1991 e 2000, o número de municípios no Brasil saltou de 4.491 para 5.561, sendo que a maioria deles tinha menos de 10 mil habitantes. Isso ocorreu porque a Constituição Federal de 1988 delegou às assembleias estaduais a prerrogativa de legislarem sobre a temática, característica do estado democrático descentralizado ${ }^{4}$.

Siqueira (2003) resume dois aspectos político-institucionais que estimularam o processo de criação de municípios: 1) o novo status conquistado pelos municípios, acompanhado de uma transferência significativa de recursos; 2) Elaboração de uma legislação, em nível estadual, que criou regras facilitadoras para as emancipações distritais. Esta combinação foi perfeita para que ocorresse novo surto emancipacionista em todo o país, processo que estaria em curso caso não fosse contido pelo governo federal.

Todavia, pelas regras postas pela Constituição Federal de 1988, o município recém-criado recebe mais recursos e não necessitaria de imediato ampliar a sua tributação. O problema é que estas transferências são fixas, um jogo de soma zero. A multiplicação esperada do número de municípios acabaria prejudicando a todos eles (WANDERLEY, 2008).

Em 1996 o governo federal se atenta aos fatos e elabora a Emenda Constitucional $n^{\circ} 15$, que inviabilizou qualquer possibilidade de novos surtos emancipacionistas no Brasil (BRASIL, 1996). Desde então, a criação de municípios ficou restrita às decisões do Judiciário. Até dezembro de 2012 o país contava com 5.565 municípios, contudo, após recorrências judiciais, o Brasil passou a contar com mais cinco novos municípios a partir de $1^{\text {o }}$ de janeiro de 2013. Assim, o país elevou o número de municípios para 5.570 .

Quase duas décadas se passaram após a Emenda $n^{\circ} 15$, e lideranças políticas dos distritos pleiteantes aguardam os trabalhos de deputados e senadores no Congresso Nacional para a aprovação da "lei de emancipações". Enquanto isso os pedidos se acumulam nas assembleias

\footnotetext{
${ }^{3}$ No final de 2013, a presidente Dilma Rousseff vetou na íntegra o Projeto de Lei Complementar 416/2008, que estabelece as novas regras para a criação, fusão, incorporação e desmembramento de municípios, ao alegar aumento das despesas sem o crescimento equivalente das receitas. Em agosto de 2014, a presidente veta novamente o projeto, o que gerou insatisfação política, inclusive da base aliada no Congresso (NUNES \& GARCIA, 2014).

${ }^{4}$ Pinheiro (2013) traz importante contribuição sobre o período de descentralização política no Brasil e sua relação com a criação de municípios.
} 
legislativas de vários estados brasileiros. Estima-se que mais de 200 distritos em todo o país reúnam as condições exigidas na nova legislação para se emanciparem (NUNES; GARCIA, 2014).

\subsection{O papel do IGTEC na criação dos distritos}

O IGTEC é o órgão estadual responsável pela redação do texto técnico da lei de criação de distritos. Neste caso, o município contrata o instituto para o estudo técnico e a câmara municipal vota o texto apresentado. Na sequência, o prefeito sanciona a lei e ordena a publicação no Diário Oficial do Estado.

Posteriormente, o IGTEC confere o texto aprovado para verificar se corresponde exatamente ao que foi proposto no estudo técnico enviado ao município. Após verificar a conformidade do texto publicado com a proposta técnica consolidada, o IGTEC comunica oficialmente a criação do distrito ao IBGE, que cria um código para o distrito e o informa ao Instituto. O IGTEC incorpora, então, o referido distrito na base oficial do estado de Minas Gerais (IGA, 2012).

Os efeitos decorrentes dos fracionamentos em distritos, e depois em municípios, requerem uma análise mais acurada para a gestão territorial. Os impactos são significativos, à medida que ocorre trocas de serviços e produtos entre as populações intermunicipais limítrofes.

O caso mais recorrente é o da educação. Não raro, alunos residentes em um aglomerado rural de um município " $x$ ” são matriculados em uma escola municipal do município "y”, sem que os pais e os próprios alunos tenham conhecimento que estão cruzando o limite intermunicipal e demandando serviço de outra administração municipal. A situação se agrava quando a distância é relativamente longa, e os pais desses alunos passam a exigir do município "y" o transporte escolar".

Qual município não demandaria uma cartografia precisa para a sua gestão territorial? Se não houver informação posicional, o limite intermunicipal pode ser preterido pelos governos municipais e acabar onerando um município em detrimento daquele que seria de fato o ofertante do serviço. Com frequência e em conformidade ao decreto que regulamenta a sua atuação, o IGTEC é acionado por autoridades municipais para dirimir problemas posicionais. Quando isso ocorre, os engenheiros agrimensores vão a campo e fazem o levantamento posicional. Só a partir de então poderão elaborar a certidão dos limites municipais.

O litígio é comum entre os municípios, notadamente, quando se trata da disputa por tributos de empresas ou outras fontes de arrecadação, cuja localização é imprecisa ou que gere dúvidas entre

\footnotetext{
${ }^{5}$ Segundo o Ministério da Educação e Cultura, a distância não pode ser superior a 2 ou 3 quilômetros até o ponto onde o veículo passa. Os itinerários devem ser fixados em função da localização da residência/escola do aluno, além de estabelecer horários adequados para buscar e levar os alunos (INEP, 2005). Curioso o caso dos municípios paulistas de Itaquaquecetuba e Mogi das Cruzes. Os alunos do primeiro município, residentes próximos ao limite intermunicipal, estão matriculados em escola pública do segundo. Eles sofriam com a falta de transporte escolar. A solução, intermediada por um repórter de TV aberta, foi que as prefeituras envolvidas dividissem o transporte escolar até o limite dos municípios. Entretanto, conforme sítio G1, em 2016 os alunos deverão ser matriculados em uma escola no município de Itaquaquecetuba (G1, 2015).
} 
as municipalidades. O exemplo escolar supracitado está na contramão dos interesses das prefeituras, pois representa mais ônus aos cofres municipais.

$\mathrm{Na}$ área da saúde isso também ocorre com certa frequência, sobretudo nas regiões metropolitanas por meio dos movimentos pendulares. Dado à proximidade entre os municípios e a discrepância da qualidade dos serviços públicos entre eles, pode ocorrer o incremento do fluxo de pacientes dos municípios mais pobres e periféricos em direção àqueles mais estruturados da capital ou de outra cidade da região metropolitana.

As demandas por serviços variam, entre outros, de acordo com o índice potencial de atração entre as localidades. Mensurá-las é um grande desafio, e esta pesquisa propõe um ponto de partida, uma metodologia parcial, descrita na seção seguinte.

\section{MATERIAL E MÉTODOS}

Ao considerar a existência de inúmeros povoados e vilas, distribuídos de forma irregular pelo vasto território mineiro, com tamanhos populacionais distintos, considerou-se mais apropriado utilizar os setores censitários do IBGE nesta pesquisa. A escolha se justifica pelo fato de que eles representam unidades espaciais com populações não tão díspares e porque nem sempre é possível aproximar-se, com acurácia, de cada vila ou aglomerado existentes.

Setores censitários não têm padrão quanto à extensão, pois na sua formação considera-se a subordinação administrativa e o número de domicílios. Isso significa que pode haver setores bem diminutos e, por consequência, com alta densidade demográfica; e também setores muito extensos, com baixa densidade demográfica. Em muitos casos em que o setor é extenso, não há uma localização pontual, exata, onde se encontram residentes. Pode ocorrer até que exista uma concentração, embora haja outros residentes espalhados. Tendo em vista a premissa de que as ocupações são difíceis de serem precisadas espacialmente, inscritas pontualmente, foram utilizados os centroides (centros geométricos dos polígonos) de cada setor censitário para representar uma média aproximada, já que não é possível estimar onde estão as maiores concentrações em cada um deles.

O Mapa 1 representa um setor censitário de 8.654ha, e os pontos são ocupações mapeadas por imagem de satélite, mostrando que seus 597 residentes não podem ser precisados em um ponto, e, portanto, tornando-se plausível o uso de uma média espacial (centroide). 


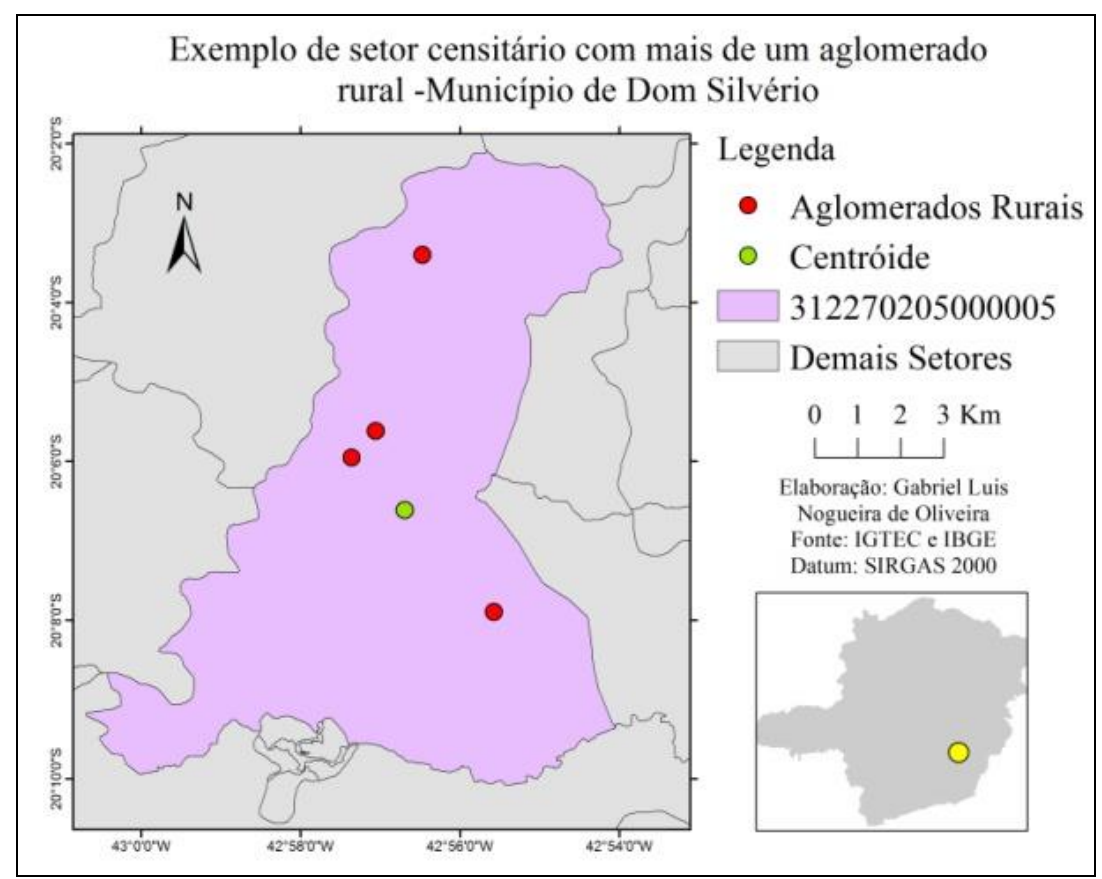

Mapa 1 - Exemplo de setor censitário - Município de Dom Silvério - MG.

A partir de um shapefile dos setores censitários de Minas Gerais, fornecido pelo IBGE, gerou-se os centroides de todos os 32.807 setores. A função utilizada é Feature to Point, disponível no software ArcMap®. Quando estão todos representados por pontos, é possível mensurar a distância entre os centroides e a sede municipal mais próxima. Com a função Generate Near Table, obtém-se uma tabela em que a primeira coluna representa cada um dos 32.807 centroides; a segunda, a sede municipal mais próxima; e a terceira, a distância em linha reta em quilômetros. Admite-se que o mais coerente seria considerar o percurso em função do acesso disponível. No entanto, grande parte dos deslocamentos realizados entre localidades e sedes é feita através de estradas não pavimentadas ou outros percursos não mapeados, o que dificulta uma análise mais precisa.

Por meio dessa tabela, ainda não se sabe os casos em que os centroides estão mais próximos à sede do município vizinho. Ao expor para o software Excel® é possível identificar os casos. Basta que se use uma coluna de referência - nesta situação, a própria coluna FID utilizada pela função Generate Near Table.

Em seguida, foi utilizada uma função de lógica simples, do tipo "sim" ou "não", tendo em vista o devido alinhamento dos dados da coluna FID com os códigos dos municípios em que estão inseridos os centroides, e também com os códigos dos municípios das sedes mais próximas. Se o código do município ao qual o setor pertence for igual ao código do município ao qual pertence a sede mais próxima, então não representa um caso. Se forem diferentes, representam um caso.

A Tabela 1 ilustra o processo com dois exemplos, um "caso" e um "não-caso", em que “fid_setor" é o FID do centroide, "fid_sede” é o FID da sede, “cod1" é o código do município no 
qual o setor está inserido, "cod2" é o código do município da sede mais próxima, e "lógica" para aferir se corresponde a um caso ou não ( 1 = não-caso e 2 = caso).

Tabela 1- Exemplos de "caso" e "não-caso" de duas localidades

\begin{tabular}{cccccc}
\hline fid_setor & fid_sede & distância & $\operatorname{cod} 1$ & $\operatorname{cod} 2$ & lógica \\
\hline 0 & 595 & $20,8 \mathrm{~km}$ & 3100104 & 3123502 & 2 \\
1 & 852 & $23,4 \mathrm{~km}$ & 3100104 & 3100104 & 1
\end{tabular}

Uma questão importante nessa análise é que os setores que estão nas sedes são considerados, o que pode parecer uma incoerência, já que obviamente estão localizados na própria sede. Todavia, todos eles são confirmados no processo como "não-casos" e extraídos do banco de dados que está sendo montado. O que prevalece é a praticidade de "rodar" a função Generate Near Table com todos os setores para depois retirar os que estão nas sedes, que já se sabia previamente que não seriam "casos".

Os "casos" presentes na Região Metropolitana de Belo Horizonte foram rastreados através dos códigos dos municípios, e depois excluídos do banco de dados ${ }^{6}$.

As demais etapas da metodologia correspondem à montagem do banco de dados, que é constituído por variáveis distintas. São acrescidos aos "casos" os dados de: código do setor; tipo (rural/urbano); nome do município no qual o setor está inserido; nome do município da sede vizinha; mesorregião; população do setor; população da sede vizinha; número de unidades básicas de saúde no município em que o setor se encontra e no município vizinho; número de instituições públicas de ensino, na sede do município do setor e na sede do município vizinho.

Os "casos" foram sumarizados por mesorregiões: frequência, porcentagem, razão da frequência/número de municípios e razão da frequência pela área total da mesorregião. Essas informações serão apresentadas na seção seguinte, bem como a explanação dos resultados.

Ao shapefile dos centroides foi anexada a coluna de identificação de "casos" e "não-casos" (valor 2 e 1, respectivamente). Tal operação no ArcMap ${ }^{\circledR}$ chama-se Join Attribute Table. Depois são selecionados apenas os pontos com valor 2 na coluna de identificação, através da operação Select by Attributes, e, por fim, são exportados, ao criar um shapefile apenas para os casos.

A forma utilizada para expressar a ocorrência de fenômenos pontuais é através do cálculo de densidade de Kernel. Esse cálculo foi realizado com o shapefile de casos, também através do ArcMap®.

O produto de todo esse processo explicado até aqui na metodologia é um banco de dados no qual podem ser adicionadas outras informações referentes a serviços públicos oferecidos nas sedes, como educação e saúde.

${ }^{6}$ Os casos da RMBH não constituíram demanda para o projeto de pesquisa, daí a exclusão dos casos. 
Não obstante este trabalho ser uma proposta metodológica e não tenha a finalidade de explorar e estimar os deslocamentos humanos que são realizados entre as localidades e as sedes municipais vizinhas, ainda assim é importante para subsidiar outras possibilidades de estudos que contemplem o setor de serviços. Outras possibilidades podem ser exploradas tais como: compreender as motivações dos deslocamentos entre as localidades; identificar a acessibilidade entre as localidades e a qualidade dos fluxos; identificar as precariedades na oferta de serviços e mensurar possíveis prejuízos aos cofres municipais advindos de demandas externas ao município, entre outros.

\section{RESULTADOS E DISCUSSÕES}

O número de casos levantados em que o centroide do setor censitário está mais próximo à sede do município vizinho foi de 3.209. E o total de setores (desconsiderando os da Região Metropolitana de Belo Horizonte) foi de 24.963. Logo os casos correspondem a $12,85 \%$ do total. A Tabela 2 mostra as frequências dos "casos" de acordo com a mesorregião.

Tabela 2- Frequência absoluta e relativa dos “casos" por mesorregião

\begin{tabular}{lcc}
\hline \multicolumn{1}{c}{ Mesorregião } & Frequência & $\%$ \\
\hline Central Mineira & 74 & 2,30 \\
Vale do Mucuri & 112 & 3,49 \\
Noroeste de Minas & 130 & 4,05 \\
Oeste de Minas & 138 & 4,30 \\
Campo das Vertentes & 149 & 4,64 \\
Jequitinhonha & 263 & 8,20 \\
Triângulo Mineiro/Alto & 266 & 8,29 \\
Paranaíba & & \\
Metropolitana de Belo & 282 & 8,79 \\
Horizonte & 371 & 11,56 \\
Sul/Sudoeste de Minas & 411 & 12,81 \\
Zona da Mata & 473 & 14,74 \\
Norte de Minas & 540 & 16,83 \\
Vale do Rio Doce & &
\end{tabular}

Fonte: Dados tabulados por Gabriel Oliveira.

A organização por mesorregião permite inferir que a fragmentação administrativa em cada uma delas é bastante distinta. Da mesma forma, o número de localidades como vilas e aglomerados rurais também não são similares.

Os subitens a seguir mostram algumas tendências em curso no estado de Minas Gerais, em função das sucessivas fragmentações territoriais. 


\subsection{Primeira Tendência}

Com o auxílio do cálculo da densidade de Kernel é possível visualizar a distribuição espacial dos fenômenos e observar as suas contiguidades. Os dois mapas a seguir se comunicam, propriamente, pela relação entre dois fenômenos. O primeiro, da distribuição dos casos levantados; o segundo, da distribuição das sedes municipais. A relação mostra que a fragmentação está diretamente relacionada com o fenômeno estudado, embora não seja uma correlação completamente proporcional.

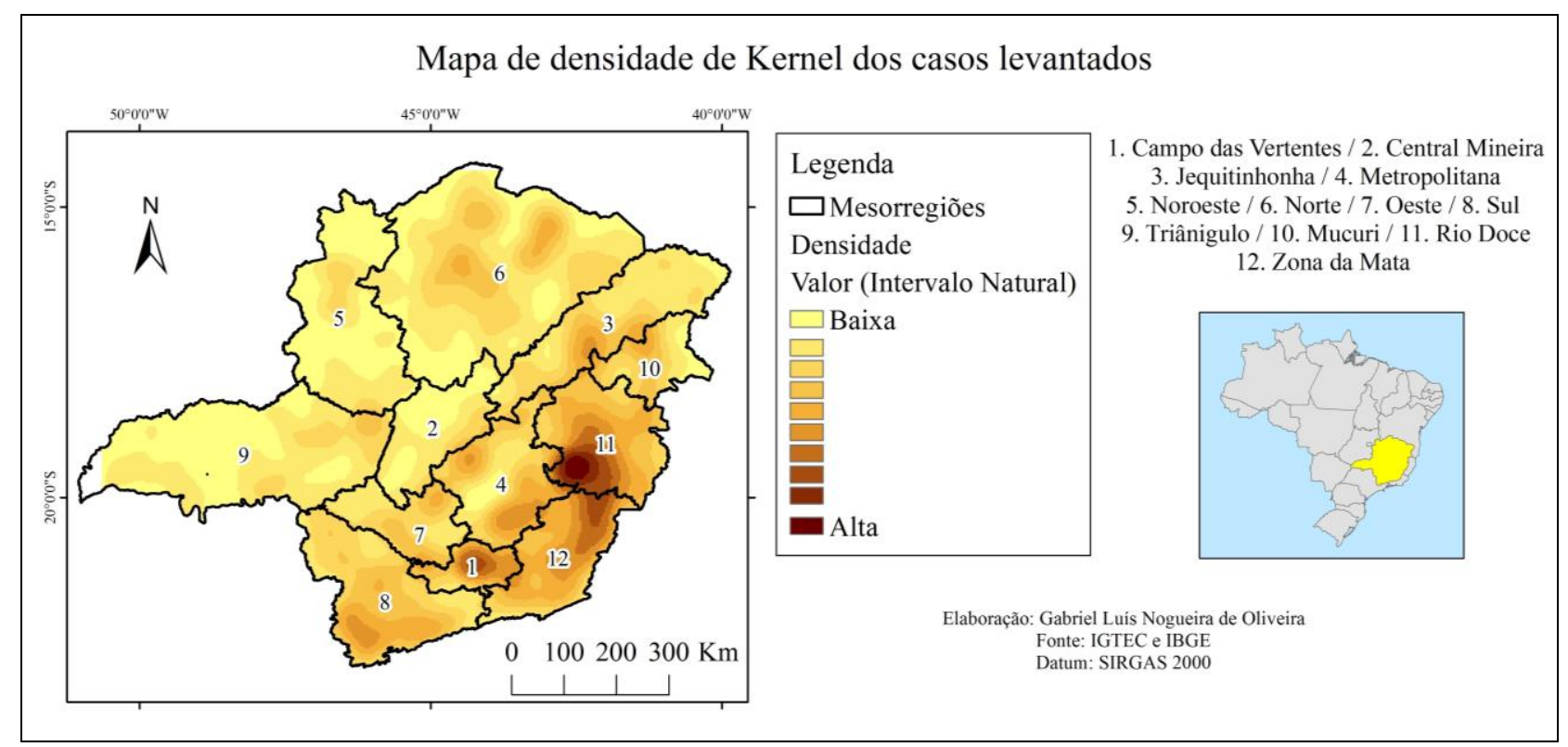

Mapa 2- Densidade de Kernel dos “casos” levantados

Tem-se, portanto, a primeira das duas tendências antagônicas que condicionam a existência desses casos: a multifragmentação municipal. A lógica que se faz presente nessa tendência se manifesta principalmente nas mesorregiões do Vale do Rio Doce, Campo das Vertentes, Zona da Mata, Metropolitana e Sul de Minas.

Ao dividir as frequências pela área total das mesorregiões, obtém-se a razão de casos por área. Percebe-se que essas mesorregiões citadas apresentam as maiores razões frequência/área. A Tabela 3 mostra essa razão, que foi calculada usando a área $\left(\mathrm{km}^{2}\right)$ obtida dos polígonos das mesorregiões no ArcMap ${ }^{\circledR}$, depois ponderados pela divisão por 100.

As mesorregiões com as maiores razões são aquelas cuja média da área municipal são justamente as menores (Tabela 4), o que evidencia a lógica das proximidades em função da fragmentação. Ou seja, quanto menores forem os municípios, maior a probabilidade das sedes estarem mais próximas de localidades circunvizinhas. 


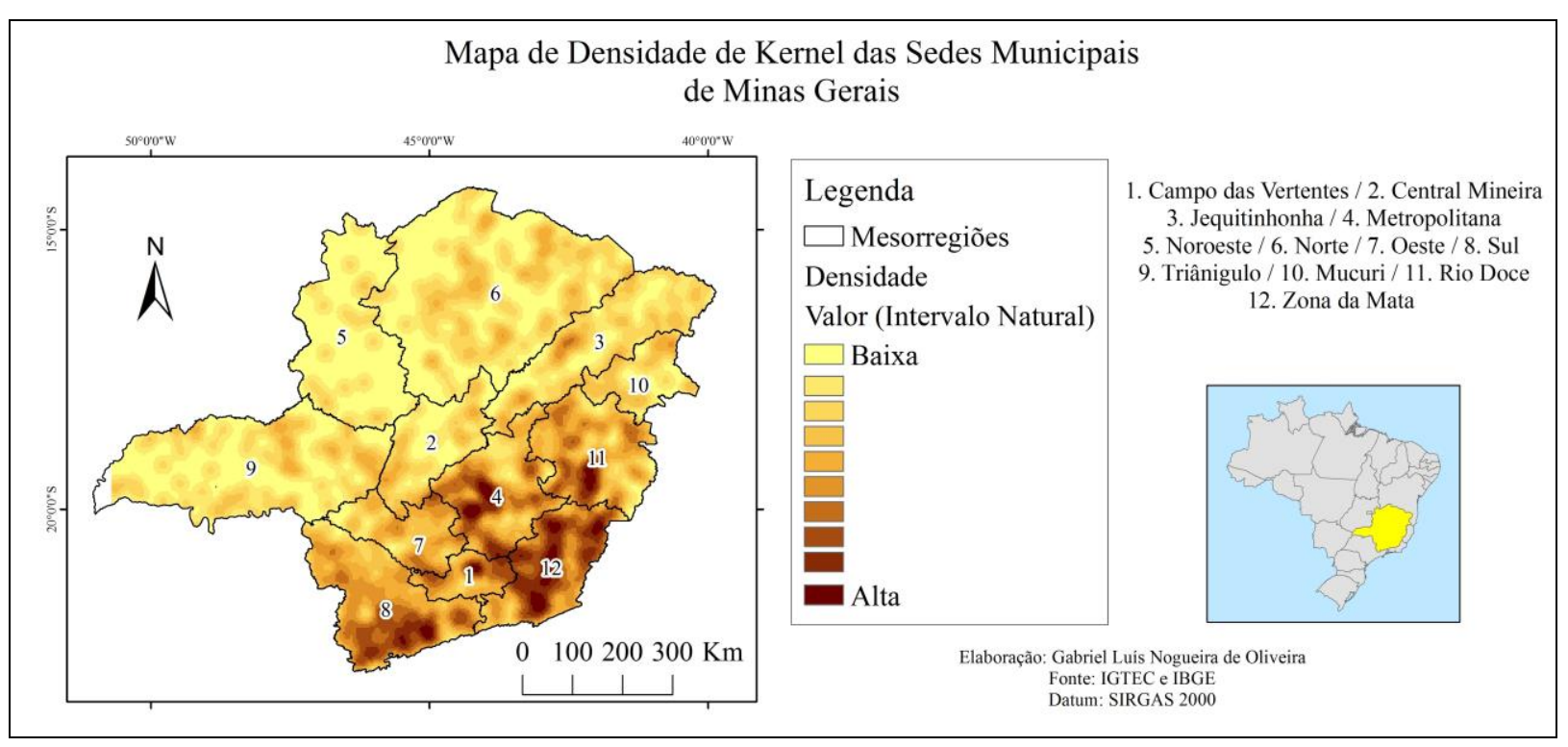

Mapa 3- Densidade de Kernel das sedes municipais mineiras

Tabela 3- Frequência relativa da razão do número de casos por área

\begin{tabular}{lc}
\hline Mesorregião & Freq./Área \\
\hline Noroeste de Minas & 0,21 \\
Central Mineira & 0,23 \\
Triângulo Mineiro/Alto Paranaíba & 0,29 \\
Norte de Minas & 0,37 \\
Jequitinhonha & 0,52 \\
Vale do Mucuri & 0,55 \\
Oeste de Minas & 0,57 \\
Sul/Sudoeste de Minas & 0,75 \\
Metropolitana de Belo Horizonte & 0,94 \\
Zona da Mata & 1,15 \\
Campo das Vertentes & 1,19 \\
Vale do Rio Doce & 1,29
\end{tabular}

Fonte: Dados tabulados por Gabriel Oliveira.

Tabela 4- Área média municipal $\left(\mathrm{km}^{2}\right)$ segundo as mesorregiões de Minas Gerais

\begin{tabular}{lc}
\hline Mesorregião & $\begin{array}{c}\text { Área média municipal } \\
\left(\mathrm{km}^{2}\right)\end{array}$ \\
\hline Noroeste de Minas & $3.292,89$ \\
Central Mineira & $1.057,43$ \\
Triângulo Mineiro/Alto Paranaíba & $1.375,03$ \\
Norte de Minas & $1.442,54$ \\
Jequitinhonha & 985,37 \\
Vale do Mucuri & 879,13 \\
Oeste de Minas & 545,95 \\
Sul/Sudoeste de Minas & 339,33 \\
Metropolitana de Belo Horizonte & 423,85 \\
Zona da Mata & 251,70 \\
Campo das Vertentes & 349,22 \\
Vale do Rio Doce & 410,05
\end{tabular}

Fonte: IGTEC. Dados organizados por Gabriel Oliveira. 


\subsection{Segunda Tendência}

Se os valores das frequências forem divididos pelo número de municípios, a questão da correlação entre densidade de casos e densidade de sedes deve ser relativizada. O que se infere é que nem sempre a maior fragmentação provoca a maior ocorrência do fenômeno. Eis a segunda tendência, em que a baixa fragmentação municipal induz à ocorrência de casos, antagonicamente à primeira, conforme apresenta a Tabela 5.

Tabela 5- Frequência do número de casos segundo as mesorregiões de Minas Gerais

\begin{tabular}{lc}
\hline \multicolumn{1}{c}{ Mesorregião } & Freq./N Mun. \\
\hline Central Mineira & 2,47 \\
Sul/Sudoeste de Minas & 2,54 \\
Zona da Mata & 2,89 \\
Oeste de Minas & 3,14 \\
Metropolitana de Belo Horizonte & 3,97 \\
Triângulo Mineiro/Alto Paranaíba & 4,03 \\
Campo das Vertentes & 4,14 \\
Vale do Mucuri & 4,87 \\
Jequitinhonha & 5,16 \\
Vale do Rio Doce & 5,29 \\
Norte de Minas & 5,31 \\
Noroeste de Minas & 6,84 \\
\multicolumn{1}{c}{ Fonte: IGTEC. Dados organizados por Gabriel Oliveira. }
\end{tabular}

Ao analisar, mais uma vez, sob a ótica da distribuição em função da fragmentação territorial, as mesorregiões Norte e Noroeste de Minas revelam que a frequência não tem relação direta com a quantidade de municípios. Em tese, como se percebe nos mapas de densidade, quanto maior a quantidade de municípios, mais casos foram confirmados. Contudo, a realidade dessas mesorregiões é a ocorrência de poucos municípios para muitos casos (razão entre frequência/n $\mathrm{n}^{\circ}$ de municípios). $\mathrm{O}$ Noroeste de Minas possui apenas 36 municípios, e o Norte, 89. Números bem inferiores que os das mesorregiões Sul e Zona da Mata, que possuem, respectivamente, 146 e 142. Teoricamente, para cada sede existente nessas mesorregiões, maior seria a quantidade de localidades dispostas nas proximidades.

A mais plausível explicação para a maior razão entre frequência e número de municípios, constatada na região menos fragmentada, é a existência de algumas poucas sedes com uma grande quantidade de localidades próximas. Isso eleva o valor da razão, mesmo que muitas das sedes sejam possivelmente bastante isoladas de qualquer vila ou aglomerado. Na verdade, em direção contrária à 
tendência percebida nos mapas de Kernel, a menor fragmentação de municípios também provoca um aumento na ocorrência do fenômeno.

O exemplo ótimo dessa inversão na lógica é o município de João Pinheiro, localizado na mesorregião Noroeste. Apenas nesse município, existem 24 setores (7 urbanos e 17 rurais) que estão distantes da própria sede. João Pinheiro é justamente o maior município de Minas Gerais, cuja sede está localizada próximo ao limite ocidental. Com isso, muitos setores acabam ficando isolados, pois nem as próprias sedes dos municípios vizinhos estão tão próximas assim.

No Mapa 4 observa-se que a sede do município de João Pinheiro está distante da área central do território. Isso é uma razão para incrementar ainda mais o número de casos, objeto desta análise.

O município de Unaí, também pertencente à mesorregião Noroeste, é outro bom exemplo. Trata-se do segundo maior município do estado, e também o segundo com o maior número de centroides de setores mais próximos das sedes de outros municípios. Ao todo constituem 41 casos.

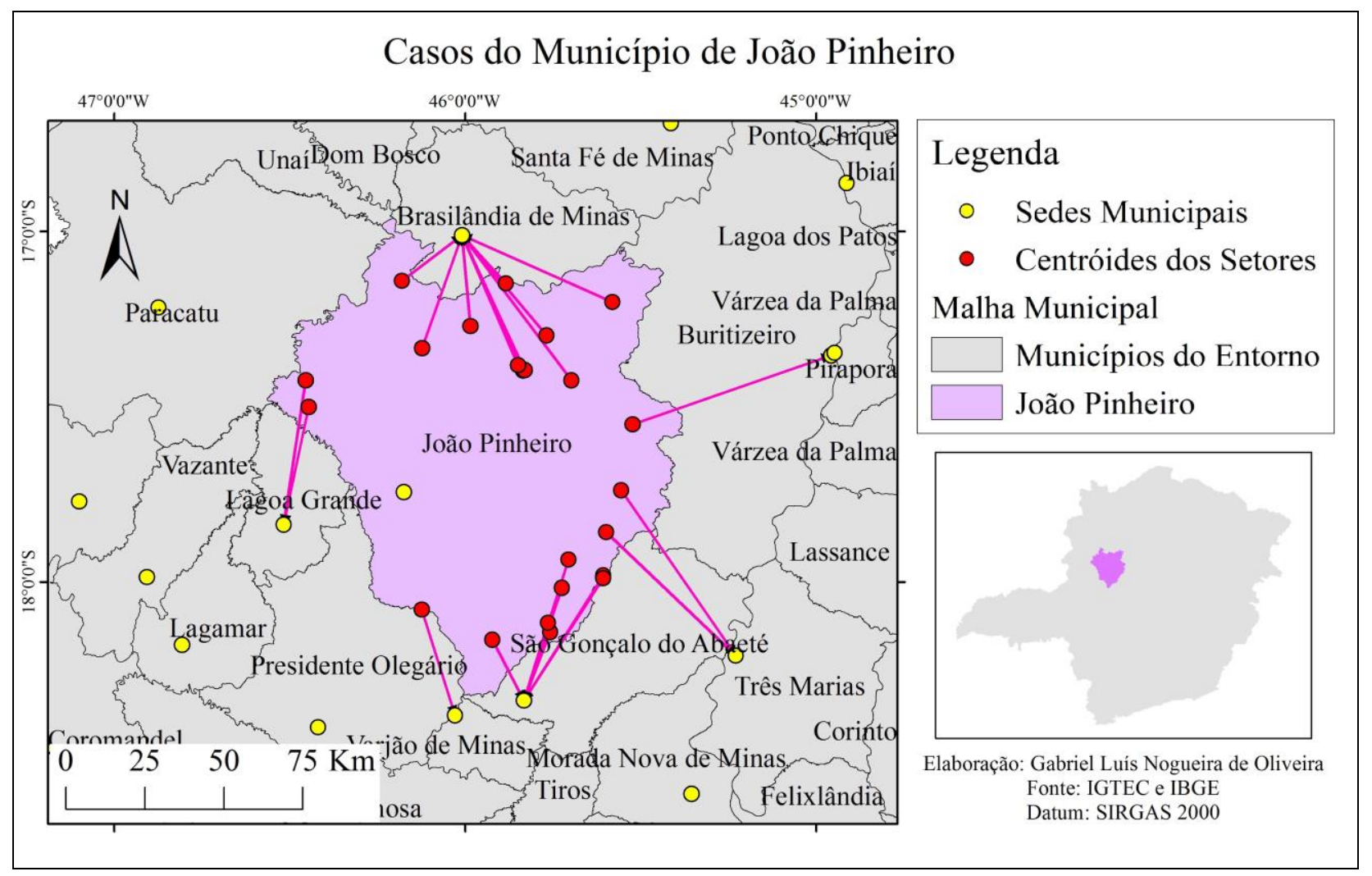

Mapa 4- Ocorrência de "casos” no município de João Pinheiro - MG

\subsection{Modelo para ocorrência de casos}

Quando essas tendências de ocorrência de casos foram observadas, considerou-se a possibilidade de criar um modelo que descrevesse a maneira como os casos tendem a acontecer. Basicamente, sabendo-se que ocorrem mais casos em função dos dois extremos do fenômeno da fragmentação territorial, o modelo possível poderia ser descrito por um gráfico cujo eixo X seria a 
média do tamanho dos municípios em cada mesorregião (quanto menor a média, mais fragmentada é a mesorregião) e cujo eixo Y seria o número de casos por municípios. A hipótese levantada seria de que o modelo tivesse uma aparência próxima ao que descreve o Gráfico 1.

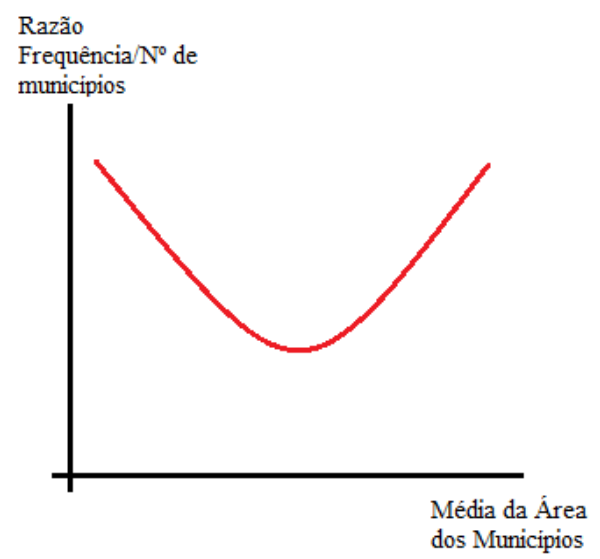

Gráfico 1- Modelo representativo - forma em "U"

Embora essas tendências descritas nos itens anteriores tenham sido confirmadas por situações específicas e frequentes (como a situação do município de João Pinheiro), ao cruzar os dados da razão frequência/n $n^{\circ}$ de municípios e a média da área dos municípios, a hipótese não foi confirmada.

O fato é que não existe um padrão para a ocorrência de casos, e sim fatores isolados que podem resultar em valores mais ou menos elevados. O cruzamento dos dados resultou no modelo expresso pelo Gráfico 2.

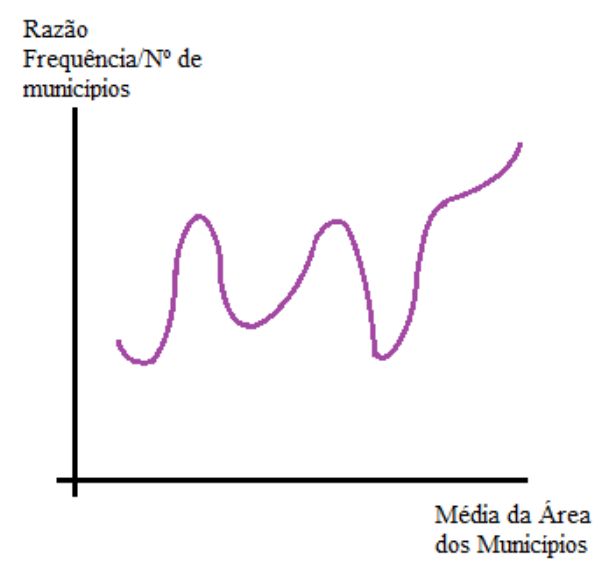

Gráfico 2- Modelo representativo - sem padrão

Como se observa, não se percebe lógica ou padrão no comportamento da linha do gráfico. Quais seriam, pois, os fatores isolados que não permitem a constatação de padrões de ocorrência de casos? A resposta foi encontrada ao analisar a malha municipal de Minas Gerais sob as camadas de casos e de sedes municipais.

Dois fatores elevam de forma pontual o número de casos em mesorregiões onde possivelmente a frequência seria baixa. São duas "anomalias territoriais": sedes localizadas muito 
próximas ao limite e municípios cuja área representa polígonos anômalos (em forma de arco ou com 'braços de território').

A Figura 1 representa um modelo fictício de divisão territorial que serve para demonstrar sob quais circunstâncias não ocorreriam casos. Os polígonos regulares e as sedes localizadas nos seus respectivos centroides, neste aspecto, inviabilizam qualquer possibilidade da existência de casos.

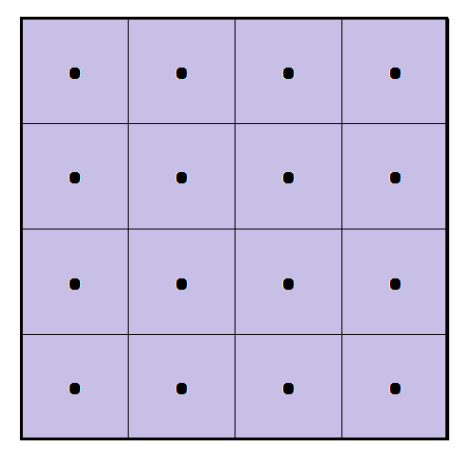

Figura 1- Modelo hipotético para não ocorrência dos "casos"

O município de Coronel Fabriciano (Mapa 5), na mesorregião do Vale do Rio Doce, tem a sede que mais se aproxima dos centroides de setores de outros municípios. Como se trata da Região Metropolitana do Vale do Aço era de se esperar tal incremento do número de casos. São 47 casos de setores próximos à sede de Coronel Fabriciano, o que corresponde a 8,7\% de todos os casos levantados na mesorregião. A razão para tal valor é a posição limítrofe de sua sede. Essa situação se repete em todas as demais mesorregiões.

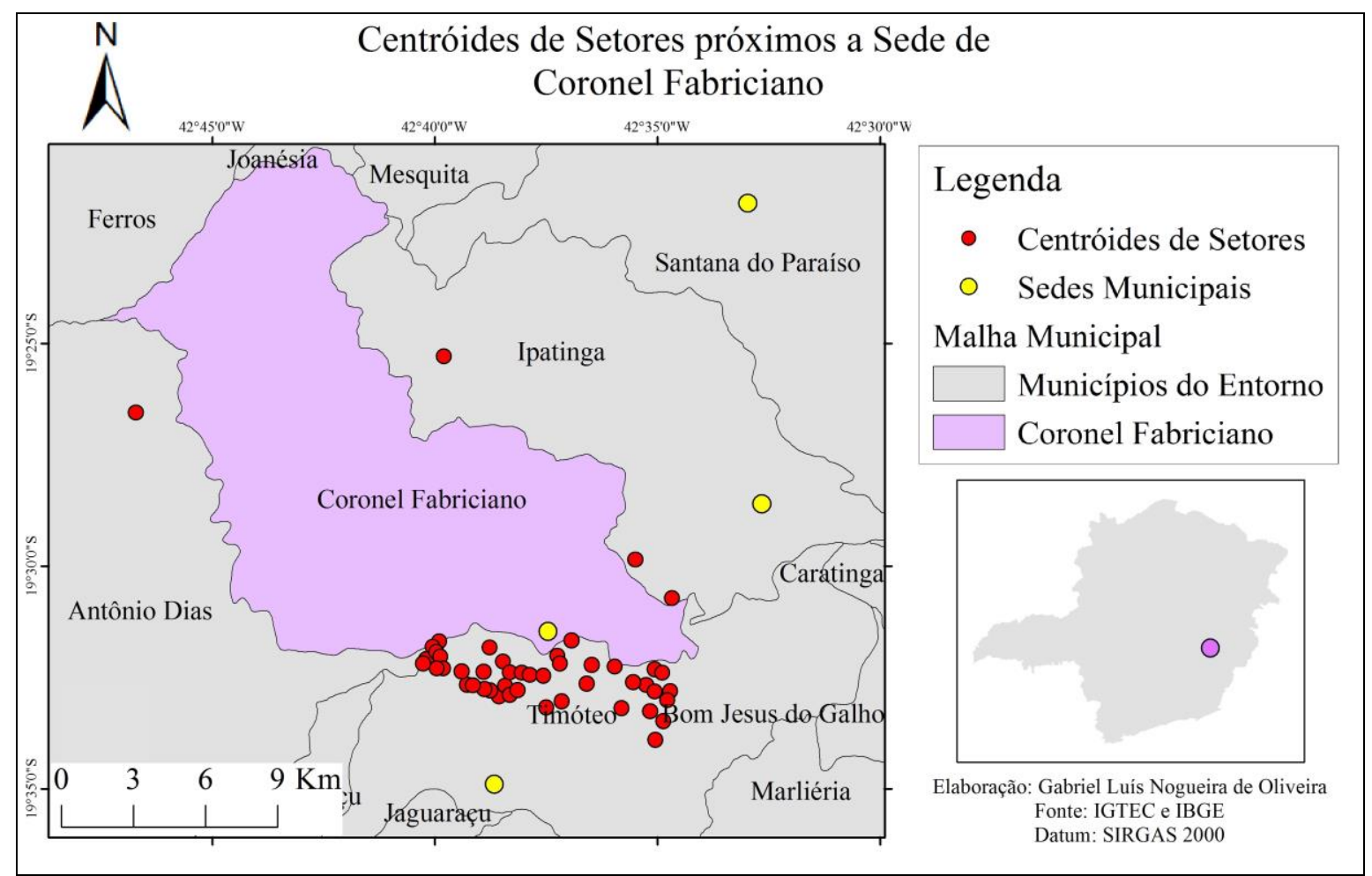

Mapa 5- Centroides dos setores censitários próximos à sede do município de Coronel Fabriciano - MG 
Quanto à situação em que o polígono do território municipal é anômalo, dois exemplos ilustram sobremaneira: o município de Caratinga e o de Curvelo. O primeiro, todavia, é o mais emblemático pela quantidade de "braços" e formas incomuns (Mapa 6). Apesar de a sede estar relativamente no centro, as áreas isoladas se aproximam de outras diversas sedes municipais. São 44 centroides de setores em Caratinga nessas condições.

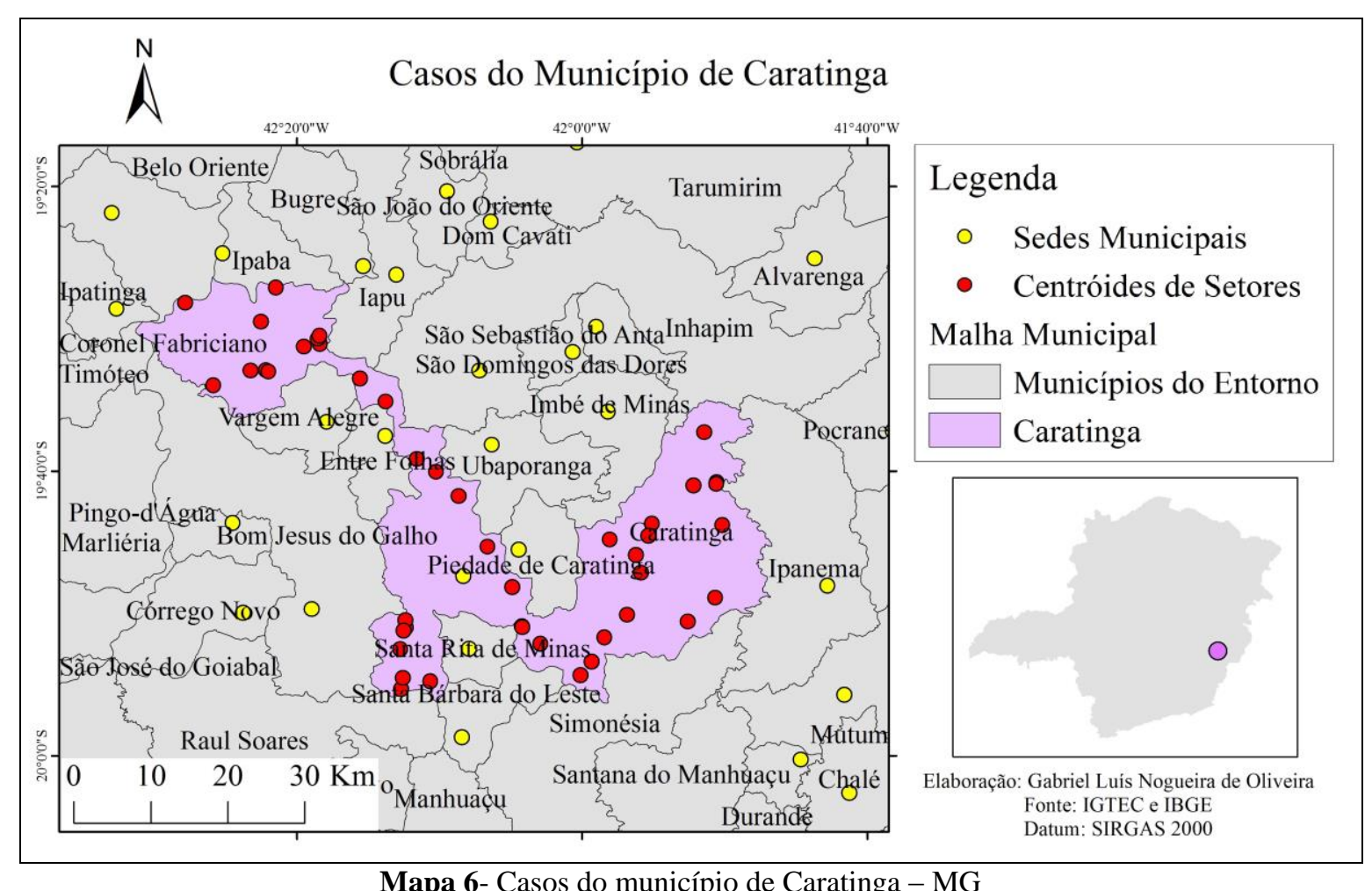

Mapa 6- Casos do município de Caratinga - MG

A média de casos por município em todo o estado de Minas Gerais é de 3,91. João Pinheiro, Unaí e Caratinga são municípios citados com ocorrência de casos bem acima da média. Também, em função da forma irregular, Curvelo possui um número de casos muito superior à média: 25 ao todo. Muitos casos ocorrem nas extremidades do seu território, conforme mostra o Mapa 7. 


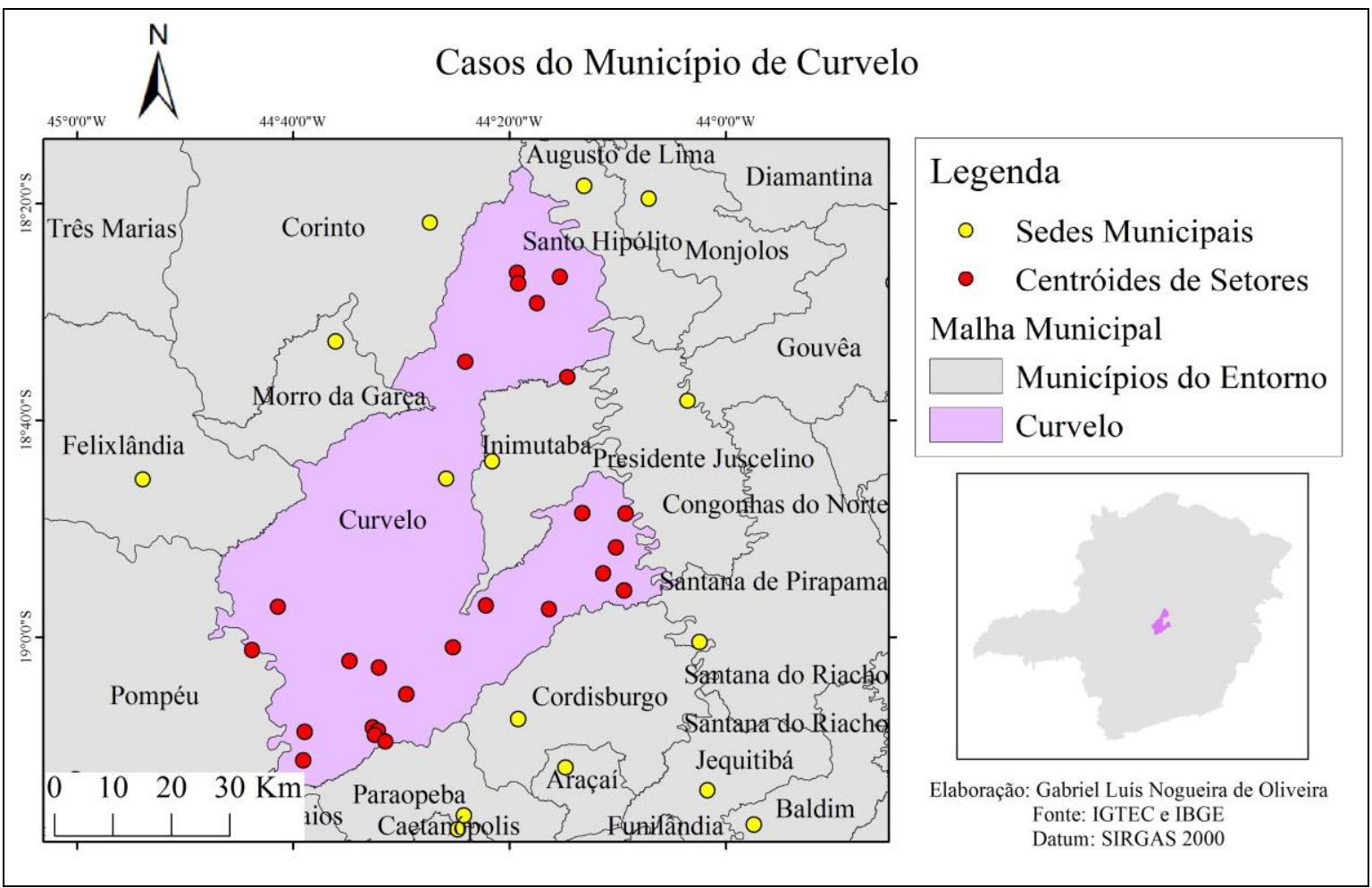

Mapa 7- Casos do município de Curvelo

Outro fator que induz ao surgimento de casos é a dispersão populacional dentro do município. Acontece em função da quantidade de setores existentes que, por seu turno, é condicionada justamente pelo tamanho da população dispersa pelo extenso território.

\subsection{Dados gerais acerca dos casos}

A soma das populações dos setores que constituem casos é de 1.305 .402 habitantes, que corresponde a $6,7 \%$ de toda a população do estado. A Tabela 6 mostra a média dos demais dados levantados.

Tabela 6- Outras variáveis de análise

\begin{tabular}{|c|c|}
\hline Variável & Média \\
\hline População da Sede do Mun. Inserido & 36.500 \\
\hline População da Sede do Mun. Vizinho & 8.452 \\
\hline $\mathrm{N}^{\circ}$ de $\mathrm{UBS}^{7}$ por Sede do Mun. Inserido & 11 \\
\hline $\mathrm{N}^{o}$ de UBS por Sede do Mun. Vizinho & 4 \\
\hline$N^{o}$ de Inst. de Ensino ${ }^{8}$ por Sede do Mun. In. & 17 \\
\hline $\begin{array}{l}\mathrm{N}^{o} \text { de Inst. de Ensino por Sede do Mun. Vi. } \\
\text { Fonte: IGTEC. Dados organizados por Gab }\end{array}$ & $\begin{array}{c}6 \\
\text { veira. }\end{array}$ \\
\hline
\end{tabular}

\footnotetext{
${ }^{7}$ Unidades Básicas de Saúde

${ }^{8}$ Apenas instituições públicas de ensino.
} 
Em geral, os municípios onde os setores-casos estão inseridos são justamente os de maior população e de oferta de serviço de educação e saúde.

\section{CONSIDERAÇÕES FINAIS}

Os fluxos de pessoas, mercadorias e serviços são condicionados pela variável distância. Todos os dias pessoas se deslocam de diversas localidades para demandar serviços de atendimento à saúde, educação, comércio, etc., de preferência em localidades mais próximas.

Por isso, a distância é uma variável importante na decisão dos cidadãos que necessitam de serviços básicos, que podem ou não ser encontrados nas sedes municipais. Se determinado serviço é oferecido na mesma condição de igualdade entre as sedes de uma microrregião, por exemplo, a variável decisiva será a distância.

Tendo em vista que uma parte significativa da população de Minas Gerais se encontra na situação de tomada de decisão relativa ao deslocamento, logo, avaliar e mensurar com mais precisão os desdobramentos desse fenômeno é de grande valor.

Por isso, este trabalho buscou compreender como e por que as localidades por vezes estão mais próximas de outras sedes. Nos resultados, pôde-se perceber que, por vezes, a organização dos limites municipais é determinante na ocorrência de casos. Isso remete às questões históricas de formação de municípios, que por sua vez está associada à história do surgimento de vilas e outras localidades.

Não é por acaso que existem municípios com formas de "istmos", "braços" e outras irregulares estéticas em seu território, bem como sedes localizadas próximas aos limites intermunicipais. Para cada história de formação de um município, existem fatores específicos que contribuíram para a delimitação territorial. Geralmente esses fatores estão relacionados aos limites de propriedades, acidentes geográficos (cursos d'água, interflúvios, etc.) e interesses políticos e econômicos.

Apenas na atualidade as administrações municipais perceberam o quanto isso impacta na gestão territorial, em razão dos deslocamentos e ônus na oferta dos serviços públicos. Há de se destacar a necessidade de estudos em níveis escalares distintos. Entender a dinâmica desse fenômeno em uma mesorregião é justificável pelas suas características específicas de formação, economia e demografia. Entretanto certos casos merecem ser apurados mais a fundo. Algumas questões não abordadas aqui podem ser contempladas para uma análise mais específica de ocorrência de casos. É importante levar em consideração a malha rodoviária ou características

\footnotetext{
${ }^{9}$ Istmos são porções de terras estreitas cercadas por água. No caso, o termo foi utilizado com a conotação de uma porção estreita de território cercada por outros territórios em ambos os lados, como o exemplo de Caratinga.
} 
socioeconômicas das populações das localidades para verificar possíveis influências nesses deslocamentos.

Ao considerar no estudo outras variáveis, é possível estimar a propensão de contingentes populacionais de recorreram a serviços em outros municípios. Esse cálculo poderá corresponder a expectativa da administração mensurar seus prejuízos e engendrar soluções. Do ponto de vista das sedes que não têm recebido os cidadãos do próprio município, a administração pública municipal poderá repensar a oferta de serviços básicos a fim de compensar o fator distância.

Por fim, o objetivo proposto na pesquisa era de apresentar uma metodologia que oferecesse respostas à existência do fenômeno analisado. Não obstante as inúmeras possibilidades de análises que podem ser feitas, uma vez de posse dessas informações, esta pesquisa não se concentrou no estudo da oferta de serviços ou o potencial das trocas comerciais entre as municipalidades. Não se nega tal possibilidade em outra ocasião. Este breve estudo serve, antes de tudo, como ponto de partida e introdução para o aperfeiçoamento da metodologia proposta.

\section{REFERÊNCIAS}

BRASIL. Emenda Constitucional $N^{o} 15$ de 12 de setembro de 1996. Dá nova redação ao $\S 4^{\circ}$ do art. 18 da Constituição Federal. Brasília, 1996. Disponível em: <http://www.senado.gov.br/legislacao/const/con1988/CON1988_12.09.1996/art_18_.shtm>. Acesso em: 8 abr. 2015.

G1. Alunos de Itaquaquecetuba ganham transporte escolar para Mogi. G1, 8 abr. 2015. Disponível em: <http://g1.globo.com/sp/mogi-das-cruzes-suzano/noticia/2015/04/alunos-de-itaquaquecetubaganham-transporte-escolar-para-mogi.html>. Acesso em: 9 abr. 2015.

IGA - Instituto de Geociências Aplicadas. Projeto Endogovernamental: Implantação do laboratório de atendimento às demandas de limites municipais e distritais de Minas Gerais. Belo Horizonte: IGA, 2012. (Proposta)

IGTEC - Instituto de Geoinformação e Tecnologia. Disponível em:

<http://www.iga.br/SiteIGA/mapas/cgi/IGA_09_BancoNoticias.php?PedeNoticia=83>. Acesso em: 6 mar. 2015.

INEP - Instituto Nacional de Estudos e Pesquisas Educacionais Anísio Teixeira. Cartilha do transporte escolar. Brasília: O Instituto, 2005. 36 p. il.

NUNES, M. A.; GARCIA, R. A. O municipalismo brasileiro e as emancipações distritais durante a década de 1990: o grau de sucesso mediante análise do IDH. In: Simpósio Mineiro de Geografia, Alfenas, maio 2014. Disponível em: <http://www.unifalmg.edu.br/simgeo/system/files/anexos/Marcos\%20Ant\%C3\%B4nio\%20Nunes.pdf>. Acesso em: 8 abr. 2015. 
PINHEIRO, T. C. A criação de municípios no Brasil nos períodos democráticos de 1946- 1964 e pós-1988: uma abordagem espacial. 226 f. Tese (Doutorado em Geografia). Belo Horizonte: Pucminas, 2013.

SIQUEIRA, C. G. de. Surgimento de municípios nos 90: a influência da distribuição populacional e do novo arranjo político-institucional no processo emancipatório paulista. III Encontro Nacional sobre Migrações, UNICAMP, Campinas, 2003. Disponível em:

<http://www.abep.nepo.unicamp.br/docs/eventos/transdisciplinar/mig_siqueira.pdf >. Acesso em: 8 abr. 2015.

WANDERLEY, C. B. Emancipações municipais mineiras ocorridas na década de 90: estimativa de seus efeitos sobre o bem-estar social. In: Anais do XIII Seminário Sobre Economia Mineira. Diamantina: Cedeplar, 2008. 